\title{
Improving Writing Skills with Systemic Functional Linguistic Approach: The Case of Vietnamese EFL Students
}

\author{
Nguyen Thu Hanh ${ }^{1}$ \\ ${ }^{1}$ English Department, Military Science Academy,-Viet Nam \\ Correspondence: Nguyen Thu Hanh, English Department, Military Science Academy, Hoai Duc, Hanoi, Vietnam.
}

Received: July 5, 2021

Accepted: July 29, $2021 \quad$ Online Published: August 4, 2021

doi:10.5430/wjel.v11n2p71

URL: https://doi.org/10.5430/wjel.v11n2p71

\begin{abstract}
This study was conducted with the purpose to identify the effectiveness of Systemic Functional Linguistic approach to improve writing skills for the EFL students at a university in Hanoi, Viet Nam. The preliminary investigation showed that most students at this university experienced many difficulties in English writing skills and they were not motivated in writing lessons. To make situation better, an action research plan was conducted with the use of quantitative and qualitative methods, focusing on applying Systemic Functional Linguistic approach, typically Theme-Rheme patterns to raise the students' awareness of Theme-Rheme benefits in creating logical text organization and then improve their writing skills. The subjects of the study were 30 students of English major at a university of foreign languages in Vietnam. The data were collected through the analysis of the students' witings, questionnaire and semi-structured interviews. The findings of the study suggested that the use of this approach could improve the students' writing skills and most of research students liked this technique because it made them motivated during English writing lessons.
\end{abstract}

Keywords: writing skills, systemic functional linguistic approach, theme, rheme, thematic progression patterns

\section{Introduction}

Over the years, the teaching of English writing has become an important topic for many Vietnamese teachers and students of English. The teaching process of English writing appears in various forms, but the main focus is on the writing of essays, the development and reference of themes. The progress of students' writing mainly relates to vocabulary range, sentence complexity and grammatical correctness and the students' style of writing is prominently influenced by Vietnamese ways of thinking, cultural factors, and mother tongue interference (Nguyen, 2009; Tran, 2007). Students encounter considerable problems in expressing themselves in different linguistic contexts and in organizing their ideas properly. Therefore, students of English not only describe language patterns separate from meaning but also ignore some structural patterns which are often found in natural texts and organized language functions to describe meanings in texts.

Systemic Functional Linguistics (henceforth, SFL) pioneered by Michael Halliday (1985, 1994, 2014) refers grammatical construction to the ways how people mean with their in-context language use. Halliday's functional approach describes how language enables us to do things and it views language as a means of creating meanings in various situations conveying information, enquiring, entertaining, arguing, sharing our experience and making sense of the world. The main concern of a SFL approach to linguistic matters centers on meaning and the usage of language to create meanings. In addition, this SFL approach does not emphasize a set of rules that commend grammatical or ungrammatical usage since language is not a fixed, supreme system but is dynamic in accordance with predetermined principles in daily use.

Of several functional structures, the Thematic structure describes the clause with its linguistic feature as a message so understanding Thematic structures in writing process becomes important for students of English (Fries, 2002; Halliday \& Matthiessen, 2014; Mellos, 2011; Tshotsho, 2014, Yasuda, 2015). Halliday's textual metafunction of language and the Theme-Rheme grammatical characteristics which are selected to use in writings describe how language conveys its meaning and why the teaching of English writing must exceed the level of sentences and grammar.

The important role of Theme-Rheme structures in the construction of a text have been proved by many studies so far. 
One of these studies that belongs Tshotsho (2014) claimed that because Theme allowed the writer to logically connect one sentence with the previous one, it was commonly seen in academic writing that the end of one clause would be the beginning of the next clause. The information introduced in Rheme would be repeated or modified as Theme of the following clause. Recently, extensive research has been conducted on the SFL grammatical features of Theme and Rhyme as effective cohesive elements at the discourse level (Fries, 2002; Leonard \& Hukari, 2005; Mellos, 2011; Wang, 2007; Wei, 2013; Unsowrth et al., 2002). Theme has been proved to play a very central part in the discourse structure and the second language writing teacher must take it into consideration. In order to improve the students' writing skills, Leonard and Hukari (2005) also emphasized the essential role of Theme and Rheme in maintaining discourse coherence. Similarly, Wang (2007) used the writing of university students to demonstrate ideas about the relationship between Theme and Rheme to improve the cohesive organization of academic papers, test the application of this method, and find ways to improve the cohesion of students' texts. In addition, Unsworth et al. (2002) discussed the improvement of writing in a second language for adults with a focus on systemic functional analysis. They mentioned that the information given or expected or familiar in the written genre was usually situated in the departure of a clause as Theme while the new information was introduced as Rheme at the end of that clause. However, few studies have been done on the employment of SFL knowledge to improve the students' writing skills, especially in the context of Vietnam.

With the above-mentioned situation of teaching and learning writing skills, particularly narrative essay writing, and the benefits of SFL approach, the current article aims to determine the effectiveness of using the SFL theory and syntactic features of Theme and Rheme during teaching the second-year English major students of a foreign language university in Vietnam to write English and to investigate their views on the SFL Theme-Rheme application in writing classes. The article then attempts to answer the two research questions: 1) To what extent does the use of the SFL grammatical features of Theme and Rheme improve the narrative essay writing skills of the second-year English major students of a foreign language university in Vietnam?; 2) What are these students' attitudes towards the employment of the SFL grammatical features of Theme and Rheme in narrative essay writing lessons?

With these aims, this study is significant for several reasons: firstly, from the SFL perspective, it is a useful investigation of employing SFL textual metafunction and Them-Rheme structure in teaching and learning narrative essay writing skills in a university of foreign languages; secondly, it hopes to transform the students' use of language from descriptive rules and structures to a functional way of linguistic understanding. This research also contributes to encourage the implementation of Halliday's SFL theory in teaching and learning English as a foreign language in Vietnam.

\section{Review of Literature}

\subsection{Systemic Functional Linguistics}

\subsubsection{General concepts of Systemic Functional Linguistics}

SFL, a theory advanced by M. K. Halliday and his partners, investigates how language is employed to convey ideas, how language is used to create meanings in order to establish social relationships through different types of texts. By analyzing the grammatical structure of the language, SFL centers on what language does and in what way it does it (Cunanan, 2011). SFL also takes social context into consideration and studies how language functions and is affected by this social context, which is different from the structured approach that focuses on the elements of language and their combinations.

Working with the SFL framework, Downing (2001) found that this system network can be used for effectively evaluating the quality of writing, since the network describes various relations between the elements that constitute the communicative events: the relation between the writers and the topic (i.e. the Ideational metafunction), between the writer and the reader (i.e. the Interpersonal metafunction) and between the writer and the text (i.e. Textual metafunction). Downing shows that the interdependent realization of Ideational, Interpersonal and Textual functions account for thematic unity in a text and that texts, which display thematic unity, in turn, become more delicate expressions of a network of semantic options defined by register and genre. Ghaleasadi (2012), Halliday and Hasan (2001) combined this point to discuss the function of text as a formal structure, which requires that the characteristics of a broader range of discourse, not just the level of individual sentences be studied, which deviates from the traditional approach. Sentence which is the most important unit of language will build up a text as a meaningful but not syntactically determined unit. The text specifies the language used in the real social environment. Text analysis can enable language users to improve their knowledge of the language system and to produce coherent meanings.

In summary, the SFL theory established by Halliday and other linguists (Cunanan, 2011; Downing, 2001; Ghaleasadi, 
2012) describes how language operates and how it is used in daily interactions. It is functionally and semantically oriented rather than a syntactically based one. It targets the whole text rather than individual sentences, and defines the scope by referencing usage rather than grammar. For non-native English learners, this theory is very important for understanding English and expressing their ideas effectively, especially in written documents.

\subsubsection{Textual Meaning and Theme-Rheme Structure}

In a clause, what will take Subject position becomes an important choice in the textual conformation of discourse; in fact, according to Halliday (1985, p.53), "the textual function of the clause is that of constructing a message" and the Theme-Rheme structure is the "basic form of the organization of the clause as message". In other words, Theme and Rheme are connected to create information flow within a text.

Of the textual metafunction of language, the system of Theme builds up the arrangement of ideas within various clauses and with the organization of a larger text (Butt, 2000). The system of Theme helps to investigate the clause structures for expressing textual meanings and showcasing the repersentation of the clause as a message. The core pattern of this organization is expressed through the sequence of the two factors of Theme and Rheme (Kobayashi, 2017). Because Theme works as the "starting point for the message" (Halliday, 1985, p. 39) or the departing position of the clause, it greatly influences on orienting listeners and readers. It is also worth mentioning that everything else in a clause that is not the Theme is called the Rheme (Halliday \& Matthiessen, 2014). In the Theme-Rheme relation, Theme provides the background for the remainder of the message or Rheme.

From a Systemic Functional approach, according to Butt (2000) and Thompson (2014), within the same clause exist three distinct subcategories of Theme, namely Textual Theme, Interpersonal Theme and Topical Theme. Different arrangements of these subcategories of Theme create a chain of Multiple Themes. Here is an example:

\begin{tabular}{|l|l|l|l|}
\hline On the other hand & maybe & the street & would be cleaner after the rain. \\
\hline Textual & Interpersonal & Topical & \multirow{2}{*}{ Rheme } \\
\hline \multicolumn{2}{|c|}{ Theme } & \\
\hline
\end{tabular}

Regarding the position of a Theme, when the Theme happens to be the Subject, it is named an unmarked Theme. However, when a circumstance or even a process instead of a participant starts the clause because something other than the Subject is emphasized, or the Theme does not correspond with the Subject, it is called a marked Theme.

Studying Theme from a broader view, various Themes work together throughout the text to create potential textual coherence. According to Thompson (2014), Theme can function as signaling the flow of "what the text is about" by repeating the same Theme as in the previous clause or picking up a constituent from the prior Rheme; marking the boundaries of the sections in the text by shifting from one Theme type to another; and signaling what is considered by the language user as an important starting point. In academic English, Themes are most often performed by nominal groups, either very long or very short. These nominal groups assist to construct semantic connections between clauses and promote general discourse flow in the text (Butt, 2000; Schleppegrell, 2004).

\subsubsection{Thematic Progression Patterns}

Regarding the previous studies on this topic, several Thematic structures exist in clausal levels and these structures define the character of a clause as a message. In general, with Thematic structures, language users can follow closely the text development in which the elements from or the meanings of Rheme in one clause are placed or repeated into the Theme of the next clause (Bloor \& Bloor, 2004; Butt, 2000). These procedures are called Thematic progression patterns (Daneš, 1974). Below are five main distinct Thematic progression patterns:

Constant progression which keeps the same topical Theme in series of clauses. New details are presented in the Rheme of each clause. For example:

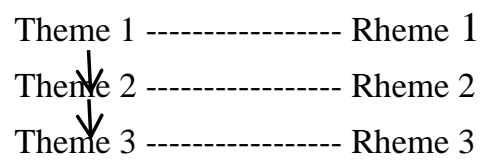

The continuous or linear progression in which Rheme portion of individual clause becomes the Theme of the following clause. For example: 
The crisscross progression happens when the second clause has the Rheme that is developed from the Theme of the first clause and the third clause has the Rheme that is developed from the Theme of the second clause and so on. Let's consider:

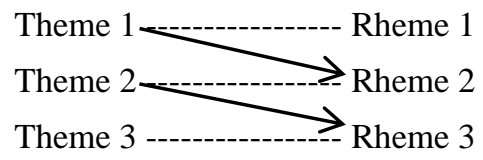

The split Rheme pattern (or multiple-Rheme pattern) in which Rheme of a clause has two or more elements and then each of these elements becomes Theme of a subsequent clause as below:

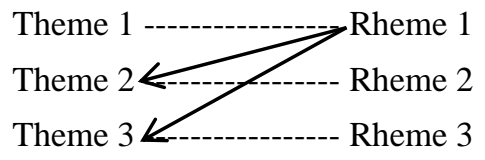

Centralized progression in which each Theme carries different new information while Rheme carries the same given information as illustrated below:

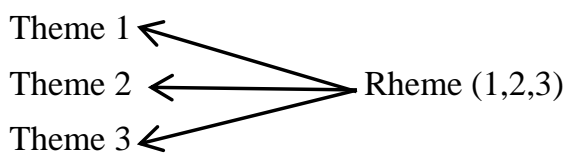

In short, the above-mentioned Thematic progression patterns are constructive for foreign language learners to regulate their thinking which then promotes the control over thematic development of various types of text and help them effectively choose various text development modes.

\subsection{EFL Writing and the Teaching of EFL Narrative Essay Writing}

\subsubsection{The Concept of EFL Writing}

Writing is a process of organizing ideas and thoughts in readable forms for communicative purposes. Hidayati (2018) claims that writing in EFL contexts is a way to produce a piece of written text using English as the foreign language in the most natural way. It is an action of employing various strategies to manage the composing process and gradually develop a meaningful text. Emilia (2010) and Zeng (2005) state that EFL writing includes several activities, namely setting goals, brainstorming ideas, making an outlinoe, selecting proper language, writing a draft, reading and reviewing it, then revising and editing. The whole process becomes complex, typically for many second and foreign language learners.

In short, writing is a communicative means of transferring thoughts and ideas in written form. Learning to write in a foreign language becomes challenges for a language learner. Therefore, in order to have a good EFL writing, some aspects of writing are taken into such as grammar as a system of rules for constructing grammatically acceptable and sensible sentences in English (Correa \& Echeverri, 2017, Wei, 2013); vocabulary referring English words chosen to express meaningful ideas; and organization as the arrangement of information into logical coherence and cohesion of a unified text.

\subsubsection{The Teaching of EFL Narrative Essay Writing}

Unsowrth et al. (2002) explain that narrative is storytelling and narrative text is a true or imaginary story conveyed to entertain readers or listeners. The writer often sets the scene first and then tells what happened according to natural time sequence. The genre of narrating or narrative is one of the most commonly read because it has a powerful social role beyond that of being of medium for entertainment as well as for changing social opinion and attitudes (Paltridge, 2001).

The teacher in teaching EFL writing can be considered as a facilitator, a coach, and a supporter who offers guidance for students to get involved in the brainstorming process of composing (Unsowrth et al., 2002). Practically, there were difficulties for EFL students in writing narrative text. The difficulties may come from the students' poor topical knowledge, mother tongue interference, inadequate grammar knowledge and vocabulary, and ineffective ways of organizing the texts. To make the writing process comfortable and successful for the students, the teacher needs to do it in a manner of respect for student's opinions and with innovative methods of teaching writing. One teaching strategy that could improve the students' EFL writing is to use Halliday's SFL theory. 


\section{Methodology}

\subsection{Research Design}

The design of this study is an action research. Mills (2007) states that action research refers to a series of procedures in which teachers can participate either because they want to improve all aspects of their teaching or because they wish to evaluate the success and/or suitability of certain teaching and learning activities. Accordingly, with an attempt to improve writing skills of the second-year English-major students of a university in Vietnam through the use of SFL theory, the study adopted a classroom action research model proposed by Kemmis and McTaggart (1988) as this model provides simplified steps of Preliminary investigation, Action plan, Implementation, and Reflection, which allow collaborative participation of both teachers and students to identify problems and design reasonable solutions so that current teaching and learning situation can be shifted appropriately and some changes can be made to the identified problems. The details of action research steps will be described in later section.

The research uses both quantitative and qualitative methods, including literature analysis, questionnaire surveys, and interviews. The questionnaire and interviews would be delivered after the completion of the implementation of SFL theory in teaching writing.

\subsection{Participants}

This research involves 30 students of English at a university of foreign languages in Vietnam (hereafter FL University). They are the second-year English majors and are studying a four-year English course. The reasons for choosing these students consist of: firstly, these participants are all students majoring in English who have completed their first year in the English Department and their English level is expected at Intermediate, good enough to understand and explore Halliday's SFL theory in their EFL writing. Secondly, "Introduction to Linguistics" is one of their compulsory subjects at the university so studying SFL certainly proves beneficial to widening their understanding of linguistics. Thirdly, these students are from the class where the researcher has been in charge of teaching English writing and reading skills for two semesters. Last but not least, though these students are keen on learning English they often struggle with language skills, typically writing skill. Therefore, the researcher decides to carry out an action research project with the SFL Theme-Rheme implementation to help improve the students' writing skills.

\subsection{Action Plan Procedures}

Kemmis and McTaggart's Action Research Model (1988) was adapted to perform this study. The research procedures were implemented for eight weeks in the following stages: Preliminary investigation, Action plan, Implementation, and Reflection. While the action research project is short-term, bounded, and related to the curriculum -mediated practices within the current educational context, the time length is important for bounding or setting limits to the research project. The duration of eight weeks, also the required time for the writing subject at EF University, is the right amount of time for the data to emerge from the process.

a) Conducting preliminary investigation: Based on the researcher's class observation and the pre-test that had been administered before the action plan began, the students' specific writing issues were investigated. The researcher then made an action plan to deal with these problems properly.

b) Developing an action plan: A thorough preparation for the work was carried out, including preparing teaching materials, lesson plans, and setting criteria for success. These criteria were created in advance as a basis to determine whether the implementation of Theme-Rheme structures was successful or not. The action would be considered effective if the students showed their significant improvement in cohesion, text organization and text development strategies. Besides, the method would be seen as efficient if at least $60 \%$ of the students felt more motivated and confident in writing lessons after the treatment. Writing objectives, requirements, instructions, and the topic lists were carefully made to implement 'SFL teaching writing' project in the class. The topics were chosen from the suggested topics in the textbook Writing 1 designed by the teachers of English at EF University, namely Travelling, Shopping, Describing People, Movies, Hobbies, Family,...

c) Implementing the action plan: The implementation period lasted 8 weeks.

+ Week 1 "Pre-SFL teaching writing" refers to the writing lessons before SFL teaching in which the students were asked to write a narrative essay of "An Important Day" in about 250 words within 40 minutes. These pieces of writing became the pre-SFL teaching data.

+ Weeks 2-3 "SFL teaching and practice": After completing the narrative essay, students received a separate SFL lesson. The lesson consisted of two parts: part 1 briefly overviewed SFL theory; part 2 focused on Theme and Rheme. 
During this SFL lesson, the explanation of the SFL feature of Theme-Rheme was provided with various examples for the students to master this grammatical feature; with classroom discussion, pair or group work, the students were asked to complete exercises designed in grammatical analysis of Theme-Rheme feature. The teacher adjusted her teaching to accommodate the students' linguistic needs. Specifically, the teacher would ask the students to start using Theme-Rheme structure with simple clauses or short paragraphs or identify Themes and Rhemes in the provided paragraphs. Later on, the students step by step developed awareness in using the Theme-Rheme patterns in their narrative essay writing.

To support the students' mastering the SFL grammatical feature of Theme and Rheme, different exercises were carefully designed to suit the learning requirements of the students as well as to the students' comments and reflections in the writing class. Here are the examples:

\section{Exercises on Theme and Rheme}

1. Determine and label the Themes in the clauses. Classify them as unmarked or marked Themes.

2. Identify different types of Themes in the following clauses.

3. With the Thematic progression patterns introduced in the lesson, reorder the clauses into a coherent paragraph. Illustrate the Thematic progression patterns into a diagram.

4. Compose a paragraph of at least 6 clauses, and then draw a diagram of the Thematic patterns.

+ Weeks 4-8 "Post SFL teaching writing": With the knowledge of SFL and Theme-Rheme structures, the students were required to write 250-word narrative essays on provided ideas and show their knowledge of the Theme-Rheme structures they have learnt for developing writing skills. In total, they had to complete 30 pieces of pre-SFL teaching essays and 30 pieces of post-SFL teaching ones. The students were required to apply the SFL and Theme-Rheme features in their writing to create writing flow and coherence.

d) Reflecting on the process: Before the final versions were handled to the teacher, the students were encouraged to work in pairs to get peer-feedback on their writing. Then the teacher gave them feedbacks by pointing out what they did well and what they failed to do. Based on the error observation, remedial works were taken and then the final work was handled in as the post-SFL teaching data. After 8 classes of Theme-Rheme methods ended, the researcher also distributed a questionnaire and conducted the interviews with the students in order to investigate their attitudes towards the employment of SFL Theme-Rheme patterns in developing writing skills.

Next, based on the criteria for a successful plan mentioned earlier, the results were valued to see whether the next cycle was needed or not. If the criteria for success were not met, the decision to continue the next action research cycle would be made.

\subsection{Data Collection Instruments}

The advantage of qualitative research as Wolcott (2009) mentioned is that it collects information in a variety of ways instead of just relying on one way to triangulate. In the current study, a single data source is not sufficient to accomplish the research purpose or meet the needs of triangulation. Therefore, apart from the data from the students' writings, the data were also collected through questionnaires and interviews.

The questionnaire includes two main parts with a total of 15 items as follows: Part 1: General understanding of SFL in which the responses are coded in the Likert scale of agreement from 1 as True, 2 as Not Sure, and 3 as False, illustrating how much the students understand SFL theory and its Theme and Rheme features; Part 2: Students' attitudes towards SFL and the applicationuse of Theme and Rheme features in which the responses are also coded with as True, Not Sure, and False, illustrating the students' views on the use of Theme-Rheme feature. The students were asked to circle the answer which best reflects their thoughts.

The interviews aim to find out the students' attitudes to learning SFL and its application in EFL writing lessons. Six students of different levels were deliberately selected, two at each level. Starting with general questions about the students' life and learning, the topic gradually changed to interview questions about the students' SFL learning, including their attitudes, perceptions, understanding of SFL Theme-Rheme theory and their applications and the effectiveness of SFL in improving their own writing skills. To comply with social norms, their interview consents had to be attained in advance.

\subsection{Procedures for Data Collection and Analysis}

The whole data collection process lasted for 8 weeks (16 45-minute periods), which was in semester I of the academic year 2020-2021 of EF University. The students were specifically required to produce 250 -word narrative 
essays with the topic given by the teacher and demonstrate their knowledge regarding Theme-Rheme features for developing writing skills. These data comprised of 30 essays written by the students before they were taught about SFL and 30 essays after SFL had been presented to the students.

It should be pointed out that collecting data from various sources was to fully understand the importance of teaching results. To this end, the researcher investigated the students' general knowledge of SFL, Theme and Rheme and their attitudes on the effectiveness of Theme-Rheme features in the form of questionnaires on developing their English writing skills. The survey was taken by 30 students and was conducted in the participant's classroom with the consent of the participants after the SFL teaching in the previous lesson. It lasted for 30 minutes and the questionnaires were collected for later data analysis.

The interviews which were informal and conducted in a very relaxed classroom setting were recorded and were later transcribed for data analysis. The researcher also noted down the talks as much as possible during the interviews. The interviewed students were coded as S1 (Student one) to S6 (Student six), (for the special situation of EF University, all interviewed students are male). The students were asked to answer open-ended questions without any time and idea constriction. Every interviewee was given an opportunity to speak so they were very willing to talk about their valuable learning experience.

Data analyses are divided into two parts: the first part covers the pre-teaching and post-teaching essays by the students to see the changes in the students' writings before and after SFL Theme-Rheme implementation in the writing lessons. The second part focuses on the students' questionnaires and informal interviews to investigate their knowledge and application of SFL Theme-Rheme patterns as well as their attitudes towards this implication in writing class. Data analysis was done with the help of SPSS and EXCEL programs.

With regard to the writing assessment, the data analysis focused only on coherence and cohesion, typically on the students' use of Theme and Rheme structures in their writings. Therefore, other error or inappropriate formula was not examined. In Theme and Rheme section, the data analysis was carried out according to the students' use of the five Thematic progression patterns such as parallel progression; continuous, linear or "zig-zag" progression; crisscross progression; split Rheme and centralized progression.

In English, different Theme choices create different shades of meanings and Themes can often support students develop their writing in term of coherence. Therefore, the analysis was conducted first by reading the students' essays to examine types of Thematic progression patterns which were used by the students in their writing and how often these patterns were used. The patterns were then grouped into different categories. Below is a sample of a student's narrative essay about "A Person You Admire" with the analysis of The Theme-Rheme pattern.

Table 1. Theme-Rheme pattern analysis of student's writing

\begin{tabular}{|l|l|}
\hline Theme (T) & Rheme (R) \\
\hline $\begin{array}{l}\text { 1. Opening the high school } \\
\text { album, }\end{array}$ & I looked at the class photo. \\
\hline 2. I & tried to recall my old days with a lot of joy. \\
\hline 3. I & Missed my friends and my beloved teacher. \\
\hline 4. These old days & were full of energy and smile. \\
\hline 5. I & $\begin{array}{l}\text { I was lucky enough to know them, especially the teacher Mrs Lien who I had admired with } \\
\text { all my respect. }\end{array}$ \\
\hline 6. I & regarded her my big sister, my mentor or even my second mother at school \\
\hline 7. I & could always go to her to seek advice, or just to have a mentor to talk to. \\
\hline 8. During her lessons, & she always chose the best ways to encourage everybody in class to improve their weak skills \\
\hline 9. With her gentle manner, & she demonstrated kindness and patience to each and every student in her class. \\
\hline 10. She & $\begin{array}{l}\text { has been an exemplary role model, and has taught me to have many strong traits about the } \\
\text { right things. }\end{array}$ \\
\hline 11. She & always taught us the need to follow discipline not only in school but also at home. \\
\hline 12. One time, & $\begin{array}{l}\text { I had fallen ill and couldn't go to school for a few days so I missed her and her lessons very } \\
\text { much. }\end{array}$ \\
\hline 13. All in all, & $\begin{array}{l}\text { I felt that the school time flew by and she has influenced me to become the best at anything } \\
\text { that I set out to be. }\end{array}$ \\
\hline $\begin{array}{l}\text { 14. With the memory of the old } \\
\text { days, }\end{array}$ & $\begin{array}{l}\text { I often come back to the school on the Teacher's Day and reunite with my friends and my } \\
\text { ideal teacher Mrs Lien who has retired now. }\end{array}$ \\
\hline 15. This & is some words about the teacher I admire and Mrs Lien is always in my heart. \\
\hline
\end{tabular}

According to Table 1, there are 15 sentences in this piece of writing. The predominant ideational topical Theme goes 
to " $I$ " which appears in sentences 2, 3, 5, 6 and 7 while in sentences $1,8,9,12,13$ and 14 , Themes are constituted by circumstances like "During her lessons" and "One time" that serve as topical Themes. "These old days" is an ideational topical Theme in sentence 4 to talk about the school years. "This" in sentence 15 as the ideational topical Theme refers to the entire text. Here are the Thematic progression patterns:

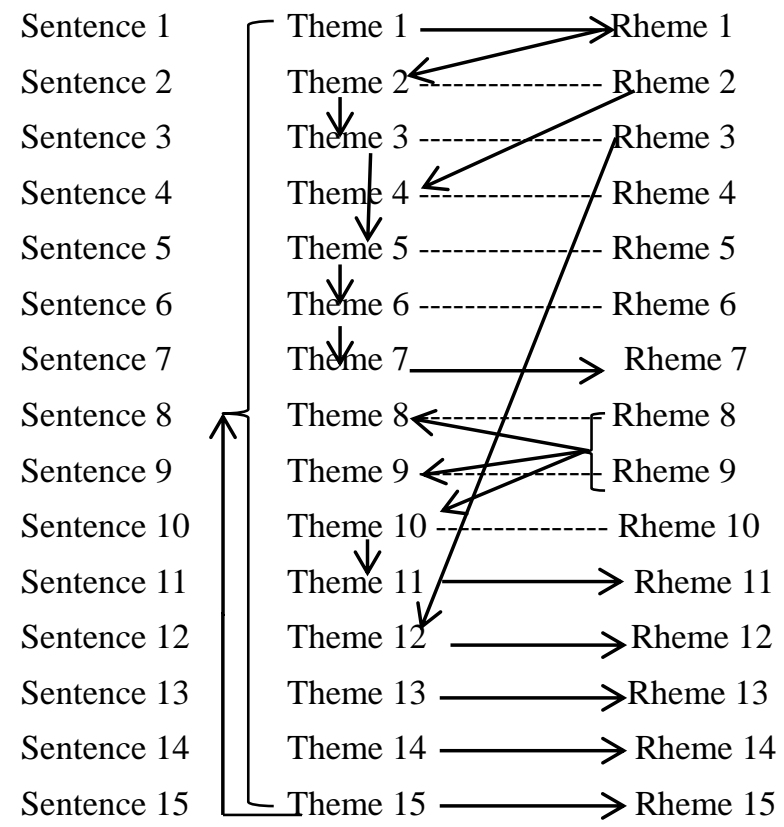

\section{Findings and Discussion}

\subsection{Findings}

\subsubsection{Findings from Pre-SFL Teaching Data and Post-SFL Teaching Data}

The purpose of analysing the data conducted on the students' writing exercises is to identify the effectiveness of students' SFL knowledge in their writings before and after the teaching of SFL and Theme-Rheme structures.

Relating to Pre-SFL and post-SFL teaching data, statistical analysis of the students' pre-SFL and post-SFL teaching essays were conducted. The mean and the total were calculated as below.

Table 2. Employment of Thematic progression patterns in the students' pre-SFL and post-SFL teaching essays

\begin{tabular}{|c|c|c|c|c|}
\hline \multirow{2}{*}{ Types of Thematic progression patterns } & \multicolumn{2}{|c|}{ Pre-SFL teaching essays } & \multicolumn{2}{|c|}{ Post-SFL teaching essays } \\
\hline & Number & Frequency & Number & Frequency \\
\hline Parallel progression pattern & 18 & $34.6 \%$ & 28 & $38.4 \%$ \\
\hline Continuous progression pattern & 12 & $23.1 \%$ & 22 & $30.1 \%$ \\
\hline Crisscross progression pattern & 5 & $9.6 \%$ & 8 & $10.9 \%$ \\
\hline Split Rheme pattern & 0 & 0 & 7 & $9.6 \%$ \\
\hline Centralised progression pattern & 6 & $11.5 \%$ & 6 & $8.3 \%$ \\
\hline Unexpected progression pattern & 11 & $21.2 \%$ & 2 & $2.7 \%$ \\
\hline Total & 52 & $100 \%$ & 73 & $100 \%$ \\
\hline
\end{tabular}

The above Table 2 illustrates the students' statistics in using Thematic progression patterns in their essays before and after the teaching of SFL and Theme-Rheme structures. According to Table 2, parallel progression pattern employment is the most popular with $34.6 \%$, followed by continuous progression pattern with $23.1 \%$. As can be seen from this table, the use of crisscross progression patterns and centralized progression patterns have nearly the same mean scores of $9.6 \%$ and $11.5 \%$ respectively. The data from Table 2 indicates that no students employed split Rheme pattern in their essays whereas the students made nearly one fourth of the progression patterns as unexpected ones (21.2\%). Relating to the writing performance after being provided with SFL theory and Theme-Rheme features, the students still used different types of Thematic progression patterns and with a higher frequency. Parallel progression patterns and continuous progression patterns were the most popular in their writing ( $38.4 \%$ and $30.1 \%$ respectively), which indicates the much higher frequency as compared to the use of these types of patterns in their pre-SFL teaching essays. The students also employed more crisscross progression patterns at the mean of $10.9 \%$. Specifically, 
split Rheme patterns which were not employed in pre-SFL teaching essays were counted for $9.6 \%$ of the total Thematic progression patterns in post-SFL teaching essays. Another interesting point is that the unexpected progression patterns were reduced to only $2.7 \%$ in post-SFL teaching essays while these patterns took $21.2 \%$ in pre-SFL teaching essays.

\subsubsection{Findings from Questionnaire}

The students' answers to Part 1 and Part 2 of the questionnaire demonstrate that, despite some exceptions, there are a lot of similarities in the students' responses to each item.

In the first part of the questionnaire which is on the students' general understanding of SFL, the students had a good understanding of SFL, the SFL textual metafunction, and Theme-Rheme structure. They could attain the basic knowledge of SFL and the content explored by SFL, as shown in Table 3 below. This reveals that the students could effortlessly understand how functional grammar developed the ways in which SFL enabled the language users to express their experience of the world, to exchange knowledge and to create coherent information.

Table 3. Illustration of students' general understanding of SFL and Theme theory

\begin{tabular}{|l|l|c|c|c|}
\hline & \multicolumn{1}{|c|}{ Question items } & True & Not Sure & False \\
\hline 1. & SFL concerns & $25 / 83.3 \%$ & $5 / 16.7 \%$ & 0 \\
\hline 2. & SFL three metafunctions & $18 / 60 \%$ & $10 / 33.3 \%$ & $2 / 6.6 \%$ \\
\hline 3. & Function of Ideational metafunction & $21 / 70 \%$ & $8 / 26.7 \%$ & $1 / 3.3 \%$ \\
\hline 4. & Function of Interpersonal metafunction & $19 / 63.3 \%$ & $9 / 30 \%$ & $2 / 6.6 \%$ \\
\hline 5. & Function of Textual metafunction & $22 / 73.3 \%$ & $5 / 16.7 \%$ & $3 / 10 \%$ \\
\hline 6. & Explorations of SFL & $14 / 46.7 \%$ & $12 / 40 \%$ & $4 / 13.3 \%$ \\
\hline 7. & Concept of Theme-Rheme & $26 / 86.7 \%$ & $4 / 13.3 \%$ & 0 \\
\hline 8. & Functions of Theme- Rheme & $28 / 93.3 \%$ & $1 / 3.3 \%$ & $1 / 3.3 \%$ \\
\hline 9. & Types of Theme & $20 / 66.7 \%$ & $7 / 23.3 \%$ & $3 / 10 \%$ \\
\hline 10. & Types of Thematic progression patterns & $18 / 60 \%$ & $8 / 26.7 \%$ & $4 / 13.3 \%$ \\
\hline
\end{tabular}

Table 3 describes the data analysis results of Part 1 from the questionnaires which was completed by all 30 students. This part covers the students' general understanding of SFL (items 1-10). Based on the Likert scale designed for Part 1 , a reasonable comprehension of the SFL characteristics and Theme-Rheme features should equal the average score of about 50\% because it is between "good understanding of SFL" and "poor understanding of SFL" and less than 50\% of the scores means the students have a lack of SFL knowledge.

The data collected also indicates that the students had very optimistic views towards the Theme theory, the role of Thematic progression patterns in writings and the use of Theme-Rheme structures in their essays except for the response to Item 6 . In Item 6 , the students' average score was 2.57 , which reveals it is difficult for students to understand how SFL investigates how English grammar enables language users to represent their own world experience, interact with each other, and typically to create coherent information.

The results from Table 3 show that the students had a good knowledge of the Theme-Rheme concept with the agreement for items 7, 8, 9, 10 are $86.7 \%, 93.3 \%, 66.7 \%, 60 \%$ respectively.

The data analysis of Part 2 is shown in Table 4 below. The data concerns the students' views towards the SFL and the Theme-Rheme employment in their writings (Items 11-15). With the Likert scale used in Part 2, "True" indicates a confident attitude towards SFL and the use of its Theme-Rheme features in the students" writings; the scale "False" implies the students do not react positively to SFL and the application of its Theme-Rheme features; and the scale "Not sure" means the students were not engaged in learning SFL and in employing its Theme-Rheme patterns in their writing. The data analysis and results are shown in Table 4 below.

Table 4. Students' attitudes towards the employments of SFL and Theme-Rheme theory in writing practice

\begin{tabular}{|c|l|c|c|c|}
\hline & \multicolumn{1}{|c|}{ Question items } & True & Not Sure & False \\
\hline 11. & Knowledge on Theme-Rheme makes it easier to develop ideas in your writing & $20 / 66.7 \%$ & $8 / 26.7 \%$ & $2 / 6.6 \%$ \\
\hline 12. & Knowledge on Theme-Rheme helps to make your writing more organized & $21 / 70 \%$ & $9 / 30 \%$ & 0 \\
\hline 13. & Applying Thematic progression patterns in writing is interesting & $18 / 60 \%$ & $5 / 16.7 \%$ & $7 / 23.3 \%$ \\
\hline 14. & Thematic progression patterns make you comfortable in developing your writing & $15 / 50 \%$ & $10 / 33.3 \%$ & $5 / 16.7 \%$ \\
\hline 15. & Thematic progression creates a coherent text & $23 / 76.6 \%$ & $7 / 23.3 \%$ & 0 \\
\hline
\end{tabular}


Table 4 shows that most students have positive attitudes towards SFL theory in application. The attitudes of the students towards the understanding of Theme (Item 11, 12) are positive. The students also showed their preference for the usefulness of Thematic progression patterns in writing (Items 13, 14, 15).

\subsubsection{Findings from Interviews}

This section presents the data analysis of the informal interviews done with six students. The students' interview data focused on their general understanding of SFL, their interests in SFL learning and its effectiveness in developing their writing skills. To evaluate the students' opinions from different angles, qualitative analysis methods of interpretation and discussion were employed. After transcribing the interview data, the researcher categorized the students' information into groups as follows: Group 1 - students' attitude towards SFL and metafunctions of language; and Group 2: students' reflection and views on the Theme-Rheme feature.

\section{Group 1: Students'attitudes towards SFL and metafunctions of language}

Looking into the responses about attitudes towards SFL, all six students interviewed agreed that SFL was scientific and very helpful in improving their writing skills. Five of them agreed that they obtained a general knowledge of SFL and the three metafunctions of language. Three of them believed that learning SFL interested them. However, two of them stated that SFL theory and SFL terms brought them some difficulties or even made them confused sometimes. Let us consider the following responses:

S1believed that it was interesting to study about SFL and he had a chance to acquire new knowledge on SFL metafunction but it was too abstract to under many SFL terms stand, saying that "The SFL features of metafunctions seem beneficial in improving my writing skills. In fact, at the beginning I have no idea about what they are. I need ...uh more time to study it and read more of them [metafunctions]". Similarly, S4 appeared to have a better understanding of SFL metafunctions and claimed learning a language was learning how to express oneself: "In general, the SFL theory seems to fascinate me and I am quite interested in the principle on the notions of what language does and how it does to convey the information".

Two students expressed negative feeling towards SFL metafunctions, claiming that concept of SFL was more complicated than the traditional grammar because it linked with meaning and function of the language which is often difficult to grasp. One of them said "I know the idea of Halliday's SFL is that language has three metafunctions: the ideational, the interpersonal and the textual. And in order to communicate properly, one need to master this set of language functions. It is a hard task" (S5).

\section{Group 2: Reflection and feedback on Theme and Rheme}

Being asked about reactions towards the teaching and learning of the Theme - Rheme structures, all of the students stated that they were quite satisfied with the knowledge. They did not have any difficulty in understanding it. S1 held that she could comprehend the Theme - Rheme concepts and S3 confirmed that she could also apply the Theme-Rheme structure in her writing; she added that "... I can also differentiate the types of Thematic progression patterns".

In addition, four of the students admitted the benefits of Thematic progression patterns to their writings. They believed that the mastery of Thematic progression patterns really assisted them to make coherent writings and build up logical sequence of events throughout the text.: S6 said "Understanding Thematic progression patterns is useful because it helps me built coherent writing and make it more organized by connecting the ideas with one another." However, four of them confessed their problems in using Thematic progression patterns, namely the mix-up on different types of Themes and limited application of Thematic progression patterns at sentence level. That means sometimes they could not connect the subsequent events coherently throughout the text.

\subsection{Discussion}

This research study developed from the researcher's interest in seeing how Halliday's SFL theory and Thematic progression patterns and teaching EFL narrative essay writing could be applied to classroom practice to improve the $2^{\text {nd }}$ year English-major students at a foreign language university in Vietnam. The research questions that guide the study focus on two interconnected questions: 1) to what extent the SFL grammatical features of Theme and Rheme improve these students' EFL narrative essay writing skills; 2) what are these students' attitudes towards the employment of such SFL-based approach in writing lessons. The following discussion elaborates on each of the findings that respond to these research questions.

Analysis of students' texts shows that the students developed an active understanding of SFL theory and Thematic progression patterns in their writings. For instance, in their post-SFL teaching essays the students employed more 
split Rheme patterns, continuous progression patterns, and crisscross progression patterns than in their pre-SFL teaching ones. This shows that after being taught about Theme-Rheme grammatical features, the students could use different types of Thematic progression patterns, namely parallel progression, continuous progression and also other Thematic progression patterns. Typically, the students could use split in particular Rheme pattern in their post-SFL teaching essays whereas no students did it in their pre-SFL teaching writing. This tendency is in line with several previous studies (Tshotsho, 2014; Unsowrth et al., 2002; Wei, 2013) which demonstrate that the diversity of Thematic progression patterns in the students' writings creates more logical coherence in the writings. The findings also indicate that the students wanted to avoid unexpected progression patterns in their writings. The other patterns like centralized progression patterns which the students found a bit challenging were used less frequently. In short, the knowledge of the Theme-Rheme grammatical features and Thematic progression patterns can support the students' use of Theme and Rheme structures in their writing progression.

Regading the students' attitudes towards the employment of the SFL-based approach in writing lessons, the responses to Part 1 and Part 2 of the questionnaire prove that the students grasp good knowledge of the SFL three metafunctions, SFL-related terms, Theme and Rheme. Very positive attitudes were shown by the students towards the conceptualization of Theme and Rheme, the functions and the use of Thematic progression patterns in their narrative essay writings. Most of the students developed a practical knowledge of SFL and shared interest in learning SFL while two students stated that they encountered difficulties in handling SFL terminology and three of them said that writing practice of SFL rather than SFL analysis made them more motivated. The students thought the Theme-Rheme features assisted them a lot to improve their writing skills, typically the skills of arranging ideas and connecting information within the texts. These findings are similar to the studies done by Downing (2001), Tshotsho (2014) and Wang (2007) who claim that, in the students' writings, Theme and Rheme patterns take an important role in maintaining coherence and cohesion in textual organization.

In short, it can be concluded that most students understand the SFL three metafunctions, SFL theory, and SFL exploration, which supports them a lot in their narrative essay writings. With this SFL-based approach, they feel active in creating more logical and coherent texts. The students also express a very optimistic thought towards SFL theory, Theme-Rheme features and the function of Thematic progression in their writings. From the students' reflection and feedback, it is encouraged that the students with SFL in mind should attempt to use its Theme-Rheme structures in their essays in spite of the fact that challenges and issues still exist.

\section{Conclusion}

This research was conducted to investigate the effectiveness of using SFL grammatical feature of Theme and Rheme in improving the narrative essay writing skills of the second-year English major students of EF University, as well as to explore their attitudes towards this teaching technique. From the findings and discussions of the study, some conclusions have been withdrawn. First, regarding the efficacy of employing Theme and Rheme patterns, it can be concluded that the students made significant improvement in writing competence, particularly in organizing ideas and connecting information. As for the students' attitudes toward the use of SFL theory and Theme and Rheme progression patterns in writing lessons, the results of the questionnaire and the interviews reveal that despite some arising difficulties, most of the students adopted positive attitudes towards this implementation in learning narrative essay writing skills.

Due to the constraints of time and materials, limitations in this paper are inevitable. First, the teaching of SFL and its Theme-Rheme features was too short for the students to fully understand the SFL related concepts and use them in writing practice. Second, it is about sample limitations. Only 30 EFL students were invited to participate in the action research project. If it had been with more students, better and more useful findings would have been revealed. Third, this study was confined to only the second-year English major students at EF University so it is not proper that these findings can be generalized to other groups of students, including the students in different universities.

With the hope of assisting the EFL students to develop a coherent writing, typically a narrative essay composition, this paper has demonstrated that applying SFL theory and Theme and Rheme patterns is a useful and practical teaching method in EFL writing. Based on the findings of the study, some pedagogical implications are suggested as follows: first, thanks to the benefits of Theme and Rheme patterns in students' writings in the aspect of cohesion and coherence, teachers should provide the students with details of SFL theory and Theme and Rheme patterns as essential input during writing process. Second, logical Thematic progression patterns lead to the inter-clause relations within a text so the teachers should encourage students to use Thematic progression patterns effectively in order not to "wander-off" in their writings. Third, although SFL theory does offer an effective method for the EFL writing teaching and learning process, students sometimes have difficulties in understanding the theory as well as some SFL 
terms. Therefore, the students should be given a chance to draft their writings in a group before they practice their composition individually. With the above suggestions, the researcher hopes that applying the SFL approach to teach writing will enable EFL students to effectively build the coherent organization of the texts and to master their lexico-grammatical selections in order to convey themselves successfully when writing narrative essays. The current study proves to be an affirmative indicator of teaching Theme and Rheme patterns to upgrade the writing skills of EFL students in Vietnam. Hence, Vietnamese teachers of English should build students' SFL awareness and teach them about Theme and Rheme features and the Thematic progression patterns, which helps raise an awareness of better text organizations and sharpen students' writing competence.

\section{References}

Bloor, M., \& Bloor, T. (2004). The Functional analysis of English (2nd edition). Oxford University Press. https://doi.org/10.4324/9780203774854

Butt, D. (2000). Using Functional Grammar: An explorer's guide (2nd edition). Macquarie University.

Correa, D., \& Echeverri, S. (2017). Using a systemic functional genre-based approach to promote a situated view of academic writing among EFL pre-service teachers. How, 24(1), 44-62. https://doi.org/10.19183/how.24.1.303

Cunanan, B. T. (2011). Using Transitivity as a framework in a stylistic analysis of Virginia Woolf's Old Mrs. Grey. Asian EFL Journal, Professional Teaching Articles - CEBU Conference, 54(4), 69-79.

Daneš, F. (1974). Functional sentence perspective and the organization of the text. In F. Daneš (Ed.), Papers on functional sentence perspective (pp. 106-128). Academia. https://doi.org/10.1515/9783111676524.106

Downing, A. (2001). Thematic progression as a functional resource in analysing texts. In M. T. Caneda \& J. Perez (Eds.), Circle of linguistics applied to communication (Vol. 5, pp. 23-42). University de Vigo.

Emilia, E. (2010). Teaching Writing: Developing Critical Learners. Rizqi Press.

Fries, P. H. (2002). Theme and new in written advertising. In G. W. Huang \& Z. Y. Wang (Eds.), Discourse and language functions (pp. 80-104). Foreign Language Teaching and Research Press.

Ghaleasadi, E. (2012) Thematization in romantic and criminal short stories in English and Persian: Implications for second language reading. Asian EFL Journal, 14(1), 298-341.

Halliday, M. A. K. (1977). Text as semantic choice in social contexts. In J. J. Webster (Ed.), Linguistic studies of text and discourse (Vol. 2, pp.23-81). Continuum. https://doi.org/10.1515/9783110839609-009

Halliday, M. A. K. (1985, 1994). An introduction to Functional Grammar. Edward Arnold.

Halliday, M. A. K., \& Hasan, R. (2001). Cohesion in English. Foreign Language Education Press.

Halliday, M. A. K., \& Matthiessen, C. (2014). An introduction to Functional Grammar (4th ed.). Edward Arnold. https://doi.org/10.4324/9780203783771

Hidayati, K. H. (2018). Teaching writing to EFL learners: An investigation of challenges confronted by Indonesian teachers. Langkawi: Journal of The Association for Arabic and English, 4(1), 21-31. https://doi.org/10.31332/lkw.v4i1.772

Kemmis, S., \& McTaggart, R. (1988). The action research planner (3rd ed). Deakin University Press.

Kobayashi, I. (2017). An approach to "meaning" from a viewpoint of Hallidayan linguistics. Cognitive Studies, 24(1), 8-15. https://doi.org/10.11225/jcss.24.8

Leonard, D., \& Hukari, T. (2005). Textual organization of academic writing. Paper presented at the CATESOL State Conference, California.

Martin, J. R. (1995). English Theme. In M. Ghadessy (Ed.), Thematic development in English texts (pp.223-258). Pinter.

Mellos, V. D. (2011). Coherence in English as a second language undergraduate writing: A Theme-Rheme analysis, Unpublished master's thesis. Department of Arts, San Diego State University.

Mills, G. E. (2007). Action research: A guide for the teacher researcher (3rd ed.). Merrill/Prentice Hall.

Nguyen, H. H. T. (2009). Teaching EFL writing in Vietnam: Problems and solutions - a discussion from the outlook of applied linguistics, VNU Journal of Science, Foreign Languages, 25, 61-66.

Paltridge, B. (2001). Genre and the language learning classroom. University of Michigan Press. 
https://doi.org/10.3998/mpub.23749

Schleppegrell, M. (2004). The language of schooling: A Functional Linguistics perspective. Erlbaum. https://doi.org/10.4324/9781410610317

Thompson, G. (2014). Introducing functional grammar (3rd ed.). Routledge. https://doi.org/10.4324/9780203785270

Tran, T. L. (2007). Learners' motivation and identity in the Vietnamese EFL writing classroom. English Teaching: Practice and Critique, 6(1), 151-163.

Tshotsho, B. (2014). Assessing students' academic writing using systemic functional linguistics at a university in South Africa. International Journal of Educational Sciences, 6(3), 425-433. Retrieved from https://doi-org.simsrad.net.ocs.mq.edu.au/10.1080/09751122.2014.11890154

Unsowrth, L., Astorga, C., \& Paul, S. (2002). Exploring the development of a narrative of personal experience in adult second language writing: a systemic functional linguistic perspective. TESOL in Context, 12(2), 20-27.

Wang, L. (2007). Theme and Rheme in the teaching organization of text: Implications for teaching academic writing. Asian EFL Journal, 9(1), 22-36.

Wei, J. (2013). Corpus-based research on topical thematic choices in Chinese and Swedish English learners' English writing. Theory and Practice in Language Studies, 3(12), 2202-2208. https://doi.org/10.4304/TPLS.3.12.2202-2208

Wolcott, H. F. (2009). Writing up qualitative research (3rd ed.). Sage Publication.

Yasuda, S. (2015). Exploring changes in FL writers' meaning-making choices in summary writing: A systemic functional approach. Journal of Second Language Writing, 27, 105-121. https://doi.org/10.1016/j.jslw.2011.03.001

Zeng, D. (2005). The process-oriented approach to ESL/EFL writing instruction and research. Teaching English in China, 28(5), 66-77.

\section{Copyrights}

Copyright for this article is retained by the author(s), with first publication rights granted to the journal.

This is an open-access article distributed under the terms and conditions of the Creative Commons Attribution license (http://creativecommons.org/licenses/by/4.0/). 